\title{
Microdrop generation and deposition of ionic liquids
}

\author{
Víctor J. Cadarso a), c), d) \\ Microsystem Laboratory, École Polytechnique Fédérale de Lausanne (EPFL), Lausanne 1015, Switzerland \\ Julia Perera-Nuñez ${ }^{\mathrm{d})}$ and Antonio Mendez-Vilas ${ }^{\mathrm{e})}$ \\ Department of Applied Physics, University of Extremadura, Badajoz 06071, Spain \\ Luis Labajos-Broncano and Maria-Luisa González-Martín \\ Department of Applied Physics, University of Extremadura, Badajoz 06071, Spain; and Networking Research \\ Center of Bioengineering, Biomaterials and Nanomedicine (CIBER-BBN), Badajoz 06071, Spain \\ Jürgen Brugger ${ }^{\text {b) }}$ \\ Microsystem Laboratory, École Polytechnique Fédérale de Lausanne (EPFL), Lausanne 1015, Switzerland
}

(Received 21 March 2014; accepted 10 June 2014)

\begin{abstract}
This work describes the use of a piezo-actuated inkjet print head with a nozzle aperture of $50 \mu \mathrm{m}$ to obtain picoliter drops of different model ionic liquids (ILs). A theoretical analysis of the microdrop generation of three model ILs is confirmed by experiments. The inkjet print process was optimized to enable a stable and reproducible drop ejection in both continuous and drop-on-demand modes by controlling the temperature of the nozzle, as well as the electrical signal sent to the piezo actuator used to generate the drops. Controlled volumes ranging from $43 \pm 3 \mathrm{pL}$ to $319 \pm 1 \mathrm{pL}$ have been achieved, with a volume control down to $3 \mathrm{pL}$. The null volatility of ILs yields an extremely high stability of the inkjet process, obtaining drops with very constant volumes during the entire print process. It also avoids the coffee staining effect observed in the deposition of conventional liquid drops. The possibility to deposit controlled volumes in a reproducible way is demonstrated here and applied to a proof-of-concept application with the aim to create dense concave optical lens arrays by replicating the deposited ionic liquid microdrops in poly (dimethylsiloxane) (PDMS).
\end{abstract}

\section{INTRODUCTION}

In the last 15 years, ionic liquids (ILs) have received an increasing interest ${ }^{1}$ in a myriad of different fields. ILs are defined as salts that form stable liquids near room temperature $\left(T_{\mathrm{R}}\right)^{2,3}$ and over a large temperature range. ${ }^{4}$ Such salts are composed of cations and anions; the former is usually an organic while the latter may be either organic or inorganic. Initially, the interest in ILs was mainly driven by the possibility to use them as custom-made green solvents. ${ }^{1,4,5}$ However, ILs have been used in different applications that go well beyond the initial interest in pure chemical application, due to their unique chemical and physical properties ${ }^{6}$ such as high electrical conductivity (up to $100 \mathrm{mS} \mathrm{cm}^{-1}$ ), negligible vapor pressure, null volatility in vacuum, low melting point, no flammability, good

\footnotetext{
Address all correspondence to these authors.

a)e-mail: victor.cadarso@psi.ch

b) e-mail: juergen.brugger@epfl.ch

${ }^{c)}$ Present address: Laboratory of Micro and Nanotechnology, Paul Scherrer Institute (PSI), Villigen PSI 5232, Switzerland.

d) J. Perera-Nuñez and V.J. Cadarso have contributed equally to the work presented in this manuscript.

e) Present address: Department of Didactics of Mathematics, University of Sevilla, Sevilla 41013, Spain

DOI: $10.1557 / \mathrm{jmr} .2014 .162$
}

thermal stability, and intrinsically smooth surface topography. ${ }^{7}$ For instance, ILs have been applied in solar cells, ${ }^{8,9}$ in super-smooth mirrors in vacuum and low pressure environments, ${ }^{7}$ in high-density data storage, ${ }^{10}$ as lubricants, ${ }^{11}$ in batteries, ${ }^{12}$ in nanocomposites for immunosensors, ${ }^{13}$ in light sources, ${ }^{14}$ and for chemical propulsion. ${ }^{15}$

In some applications, it is needed to work with small volumes of ILs, e.g., as imaging fluids for submicrometerscale monolayer patterns, ${ }^{16}$ in microreactors, ${ }^{17,18}$ as contact angle probe fluids, ${ }^{19}$ in micro- and nano-electromechanical systems (MEMS/NEMS), ${ }^{20,21}$ in micro-optical applications, ${ }^{18}$ or in a variety of sensors. ${ }^{22-25}$ However, generally the use of ILs in such applications is limited by the difficulty to obtain reproducible volumes below $0.4-0.2 \mu \mathrm{L}{ }^{17,24}$ This issue is mainly due to the exceptionally high viscosity of the ILs, ranging from $22 \mathrm{mPas}$ up to 40,000 $\mathrm{mPas}$ at $T_{\mathrm{R}} \cdot{ }^{1}$ Some attempts have been made to overcome the challenge to obtain small volumes by using electric fields to generate drops from atomic force microscope cantilever tips ${ }^{26}$ or by using diluted ionogels, instead of pure ILs, to obtain microdrops by inkjet printing (IJP) ${ }^{27,28}$ Both approaches have proven to be successful. However, the former is limited to small areas on conductive substrates, whereas the latter has not been fully studied, since only liquids with viscosities below $17 \mathrm{mPas}$ at $T_{\mathrm{R}}$ have been tested. Although IJP is well known to be 
a cost-effective and flexible method for the structuring of functional materials, such as polymers, ${ }^{29,30}$ no detailed study of its application for the formation of IL microdrops has been found in the open literature up to date. IJP has several key advantages such as rapid prototyping capability, high precision dispensing, noncontact multi-material deposition, low material waste, and $3 \mathrm{D}$ patterning. ${ }^{31}$ It is thus relevant to study ILs in relation to IJP for many potential applications.

In this work, microdrop formation of ILs using IJP is studied in detail and experimentally demonstrated. Different ILs with viscosities between $47.4 \mathrm{mPas}$ and $>500 \mathrm{mPas}$ have been used. A dimensionless analysis of three of the tested ILs allowed us to determine the range of temperatures at which it is possible to achieve microdrop formation even for very high viscosity ILs. The IJP process is tested in the predicted temperature $(T)$ range using piezoelectric IJP head with a heated nozzle tip (aperture of $50 \mu \mathrm{m}$ ). The process is optimized to obtain stable and reproducible microdrops with the smallest possible volumes. Drop-ondemand (DoD) IJP, defined in this work as the formation of a single or a precise number of stable and reproducible microdrops, is also performed to demonstrate the possibility to deposit controlled volumes onto a substrate in precise positions. Finally, concave optical microlenses are fabricated replicating the deposited IL microdrops in poly(dimethylsiloxane) (PDMS) as a proof-of-concept application.

\section{EXPERIMENTAL}

\section{A. Materials}

All the ILs used in this work were purchased from Sigma-Aldrich and used as received: 1-ethyl-3-methylimidazoliumtetrafluoroborate ([EMIN] $\left.\left[\mathrm{BF}_{4}\right]\right), 1$-butyl-3methylimidazolium tetrafluoroborate ([BMIM] $\left[\mathrm{BF}_{4}\right]$ ), 1-hexyl-3-methylimidazoliumtetrafluoroborate ([HMIM] $\left.\left[\mathrm{BF}_{4}\right]\right), 1$-decyl-3-methylimidazolium tetrafluoroborate [DMIM] $\left[\mathrm{BF}_{4}\right]$, 1-ethyl-3-methylimidazolium chloride ([EMIM][Cl]), 1-hexyl-3-methylimidazolium chloride ([HMIM][Cl]), 1-butyl-3-methylimidazolium hexafluorophosphate ([BMIM] $\left[\mathrm{PF}_{6}\right]$ ), and 1-butyl-3-methylimidazolium methyl sulfate ([BMIM] $]\left[\mathrm{CH}_{3} \mathrm{SO}_{4}\right]$ ).

The substrates onto which we deposited the IL microdrops were polystyrene (PS) (Goodfellow Cambridge Ltd., Huntingdon, England) and silicon ( $\mathrm{Si}$ ) wafers $525 \mu \mathrm{m}$ thick. PS was used as received, while $\mathrm{Si}$ was used either as received or modified by a self-assembly monolayer (SAM) process performed by the evaporation of a trichloro $(1 \mathrm{H}, 1 \mathrm{H}, 2 \mathrm{H}, 2 \mathrm{H}$-perfluorooctyl)silane $97 \%$ (Sigma-Aldrich) at $110{ }^{\circ} \mathrm{C}$ for $30 \mathrm{~min}$.

PDMS (Sylgard 184, DOW Corning Co., Midland, MI) was prepared by mixing the base pre-polymer with the curing agent $(10: 1, w / w)$. The mixture was introduced in vacuum for $20 \mathrm{~min}$ prior to be used to remove air bubbles. Then the liquid PDMS pre-polymer was poured over a substrate with liquid IL microdrops and cured for $1 \mathrm{~h}$ at $80{ }^{\circ} \mathrm{C}$. Afterward, the PDMS was mechanically released from the substrate. The residues of ILs were removed by immersing the PDMS replicas into acetone and using an ultrasound bath for $5 \mathrm{~min}$.

\section{B. IJP technique: Microdrop generation}

The microdrop generation of the studied ILs is performed using a heated print-head assembly (PH-46H, MicroFab Technologies, Inc., Plano, TX) with a DoD single jet dispensing nozzle (MJ-AT-01-50, MicroFab Technologies, Inc., Plano, TX) with an orifice diameter of $50 \mu \mathrm{m}$. The nozzle can be heated up to $130{ }^{\circ} \mathrm{C}$. The formation of the microdrops is observed at the tip of the nozzle using a stroboscopic camera. An image analysis software (JetLab ${ }^{\circledR}$, MicroFab Technologies) is used to determine the diameter and volume of the generated microdrops that is created by means of a periodic electrical signal sent to the piezo actuator in the nozzle. The parameters of this signal have a significant effect in the generation of the microdrops ${ }^{32}$ and have been characterized for the studied ILs in this work. Figure 1 shows the shape of the signal used in all the experiments presented in this work. Such signal can be parameterized by positive $\left(V_{\mathrm{a}}\right)$ and negative $\left(V_{\mathrm{b}}\right)$ voltages, rise $\left(t_{\mathrm{r}}\right)$, dwell $\left(t_{\mathrm{d}}\right)$, fall $\left(t_{\mathrm{f}}\right)$, echo $\left(t_{\mathrm{e}}\right)$ and final rise $\left(t_{\mathrm{rf}}\right)$ times and the frequency $(F)$. To simplify the ulterior characterization some of these parameters have been fixed; pulse amplitude (PA) and pulse length (PL) are defined as follows:

$$
\begin{aligned}
& \mathrm{PA}=V_{\mathrm{a}}-V_{\mathrm{b}}=2 V_{\mathrm{a}}, \\
& \mathrm{PL}=t_{\mathrm{d}}+t_{\mathrm{e}}=2 t_{\mathrm{d}}, \\
& t_{\mathrm{r}}=t_{\mathrm{rf}}=1 \mu \mathrm{s}, \\
& t_{\mathrm{f}}=2 \mu \mathrm{s} \\
& F=100 \mathrm{~Hz} .
\end{aligned}
$$

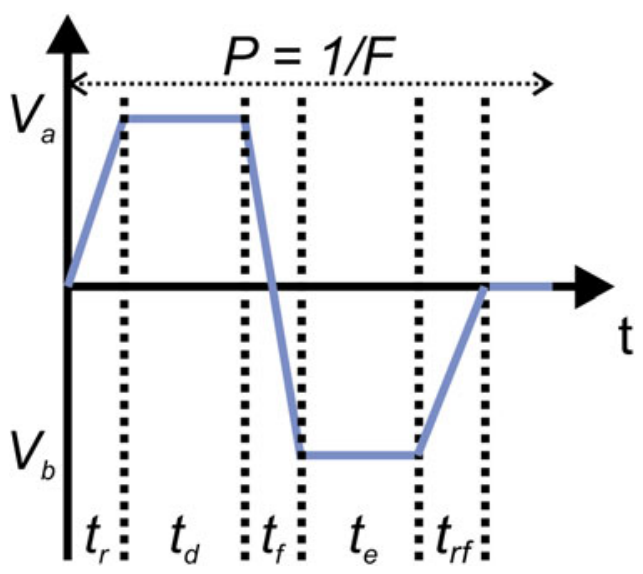

FIG. 1. Shape of the periodic signal used to generate the microdrops. 
This signal was used for continuous generation of microdrops, to characterize the microdrops in flight, and also in DoD, to prove the capacity to deposit small volumes corresponding to one single microdrop of ILs in precise positions. The positioning of the substrate was done using an X-Y motorized stage (M-ILS100CC, Newport, Irvine, CA).

\section{Dimensionless analysis of IL IJP capability}

To determine if a liquid, and in particular an ionic liquid, can be printed from a meniscus formed in a nozzle, following two conditions need to be fulfilled: The kinetic energy of the microdrop must be higher than both (i) the surface energy of the meniscus and (ii) the viscous dissipation. ${ }^{33}$ The first one is characterized by the Weber number $(W e)$, whereas the second one is represented by the Reynolds number $(R e)$. Being $d$ the diameter and $v$ the relative velocity of the microdrop; and $\rho$ the density, $\sigma$ the surface tension, and $\mu$ the dynamic viscosity of the liquid, both dimensionless numbers can be expressed as

$$
\begin{gathered}
W e=\left(d v^{2} \rho\right) / \sigma . \\
\operatorname{Re}=(\rho d v) / \mu .
\end{gathered}
$$

Both conditions can be combined in the dimensionless Ohnesorge number $(\mathrm{Oh})$, which it has been previously demonstrated that its inverse, known as the $Z$-number $(Z),{ }^{34,35}$ can be used to determine the conditions for microdrop generation ${ }^{36,37}$ since the approximate condition $1<Z<10$ must be fulfilled. For $1>Z$, break up and microdrop generation will not occur, while for $Z>10$ microdrops will be ejected but their formation will be instable, preventing their practical use.

$$
Z=1 / O h=R e /(W e)^{1 / 2}=(\rho d v)^{1 / 2} / \mu
$$

In this work, we have chosen three different ILs as model materials to characterize their inkjet ability and their volume control. The three ILs contain the same cation (1-butyl-3-methylimidazolium) [BMIM] but different anions, namely tetrafluoroborate $\left[\mathrm{BF}_{4}\right]$, methyl sulfate $\left[\mathrm{CH}_{3} \mathrm{SO}_{4}\right]$, and hexafluorophosphate $\left[\mathrm{PF}_{6}\right]$. It is possible to obtain most of their physical properties for a wide range of temperatures from the literature. ${ }^{38-40}$ The values for some temperatures are presented in Table I, labeling each IL by its anion. The selected ILs cover a range of viscosities from 109 to $376 \mathrm{mPas}$ at $T_{\mathrm{R}}$.

Using these experimental values and considering $d$ equal to the nozzle diameter $(50 \mu \mathrm{m})$, it is possible to calculate the Z-number of the three ILs versus $T$ and determine the minimum temperature required to achieve microdrop generation. As shown in Fig. 2, the minimum temperature to achieve microdrop generation is above
$40{ }^{\circ} \mathrm{C}$ for $\left[\mathrm{BF}_{4}\right]$ and close to $60{ }^{\circ} \mathrm{C}$ for $\left[\mathrm{CH}_{3} \mathrm{SO}_{4}\right]$ and $\left[\mathrm{PF}_{6}\right]$. For $\left[\mathrm{BF}_{4}\right]$, it is also possible to extrapolate the maximum temperature that will allow the generation of stable microdrops, corresponding to approximately $122{ }^{\circ} \mathrm{C}$. Furthermore, it is possible to anticipate that the generation of the microdrops behavior versus temperature changes will be mainly dominated by the viscosity change, since both density and surface tension exhibit marginal variation in the working temperature range.

\section{RESULTS AND DISCUSSION}

Microdrop generation was tested for $\left[\mathrm{BF}_{4}\right]$ for temperatures ranging between $40{ }^{\circ} \mathrm{C}$ and $140{ }^{\circ} \mathrm{C}$. Figure 3 shows stroboscopic pictures of the tip of the IJP nozzle taken $300 \mu$ s after sending the signal represented in Fig. 1 for different nozzle temperatures. As expected, for

TABLE I. Dynamic viscosity, density, and surface tension for different temperatures of the three studied ILs. Sources: for $\left[\mathrm{BF}_{4}\right]$ and $\left[\mathrm{PF}_{6}\right] \mu$ and $\rho,{ }^{38} \sigma^{39}$ and for $\left[\mathrm{CH}_{3} \mathrm{SO}_{4}\right] .{ }^{40}$

\begin{tabular}{lrccc}
\hline \hline & $T\left({ }^{\circ} \mathrm{C}\right)$ & {$\left[\mathrm{BF}_{4}\right]$} & {$\left[\mathrm{CH}_{3} \mathrm{SO}_{4}\right]$} & {$\left[\mathrm{PF}_{6}\right]$} \\
\hline & 20 & 109 & 288 & 376 \\
$\mu(\mathrm{mPas})$ & 50 & 35 & 62 & 90 \\
& 70 & 18 & 30 & 40 \\
& 100 & 8 & $\ldots$ & 15 \\
& 20 & 1.20 & 1.21 & 1.37 \\
$\rho\left(\mathrm{g} / \mathrm{cm}^{3}\right)$ & 50 & 1.18 & 1.19 & 1.34 \\
& 70 & 1.17 & 1.18 & 1.33 \\
& 100 & 1.15 & $\ldots$ & 1.30 \\
$\sigma(\mathrm{mN} / \mathrm{m})$ & 20 & 44.8 & 44.1 & 44.1 \\
& 50 & 42.9 & $40.2^{\mathrm{a}}$ & 42.2 \\
& 70 & 41.6 & $37.5^{\mathrm{a}}$ & 41.1 \\
& 100 & $39.5^{\mathrm{a}}$ & $\ldots$ & $39.1^{\mathrm{a}}$ \\
\hline \hline
\end{tabular}

${ }^{\mathrm{a} E x t r a p o l a t e d ~ v a l u e s ~ a s s u m i n g ~ a ~ l i n e a r ~ b e h a v i o r . ~}$

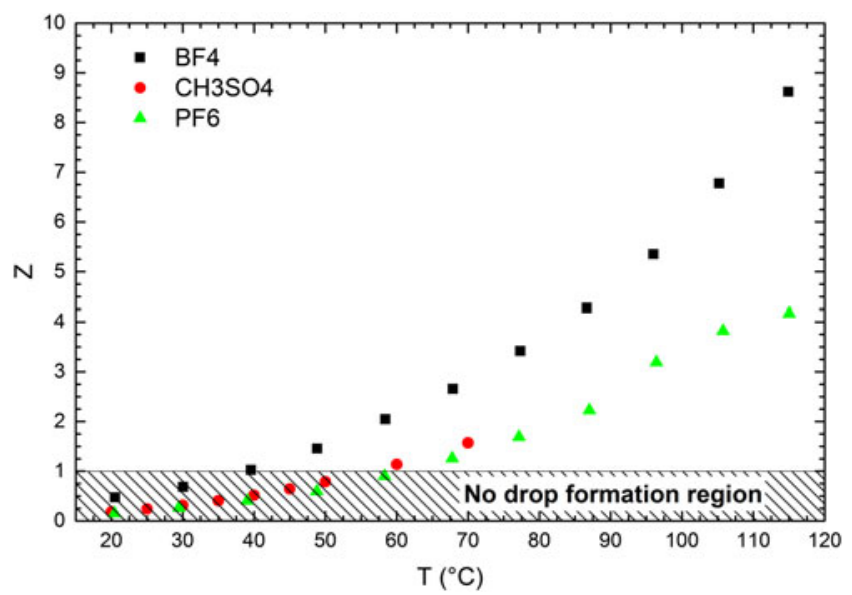

FIG. 2. Z-number of $[\mathrm{BMIM}]\left[\mathrm{BF}_{4}\right]$, [BMIM] $\left[\mathrm{CH}_{3} \mathrm{SO}_{4}\right]$, and [BMIM] $\left[\mathrm{PF}_{6}\right]$ versus temperature for a nozzle size of $50 \mu \mathrm{m}$. No microdrops can be formed for temperatures with $Z<1$. 
a temperature of $40{ }^{\circ} \mathrm{C}$ [Fig. 3(a)], no microdrops were formed. For temperatures ranging between $50{ }^{\circ} \mathrm{C}$ and $130{ }^{\circ} \mathrm{C}$, stable microdrops were formed. However, the diameter of the microdrop changes with the temperature being $64.6 \pm 0.1 \mu \mathrm{m}$ for $50{ }^{\circ} \mathrm{C}$ [Fig. 3(b)] and $44.3 \pm$ $0.8 \mu \mathrm{m}$ for $130{ }^{\circ} \mathrm{C}$ [Fig. 3(c)]. The IJP parameters were optimized for each temperature to obtain the smallest possible volume. Finally, for temperatures higher than $130{ }^{\circ} \mathrm{C}$, it was not possible to achieve stable microdrops and multiple microdrops with variable ejection conditions were formed in a single IJP cycle, as can be seen in Fig. 3 (d) for a temperature of $140{ }^{\circ} \mathrm{C}$. These results agree with the behavior expected in the theory and the calculated values for the Z-number.

The microdrop generation was also tested for $\left[\mathrm{CH}_{3} \mathrm{SO}_{4}\right]$ and $\left[\mathrm{PF}_{6}\right]$, with similar results. For both ILs, the IJP parameters were also optimized at each temperature to obtain the microdrops with the minimum possible volume. Figure 4 shows the values of $\mathrm{PA}$ and $\mathrm{PL}$ at each temperature for $\left[\mathrm{BF}_{4}\right]$ [Fig. 4(a)], $\left[\mathrm{CH}_{3} \mathrm{SO}_{4}\right]$ [Fig. 4(b)], $\left[\mathrm{PF}_{6}\right]$ [Fig. 4(c)]. The minimum temperature required to achieve microdrop generation for $\left[\mathrm{CH}_{3} \mathrm{SO}_{4}\right]$ and $\left[\mathrm{PF}_{6}\right]$ was around $60{ }^{\circ} \mathrm{C}$, as expected from the calculated values of the $\mathrm{Z}$-number. The generation of nonstable microdrops for $\left[\mathrm{CH}_{3} \mathrm{SO}_{4}\right]$ at temperatures above $130{ }^{\circ} \mathrm{C}$ was also observed. Conversely, for $\left[\mathrm{PF}_{6}\right]$, it was not possible to obtain microdrops at temperatures above $110^{\circ} \mathrm{C}$ because it started to corrode the nozzle, preventing its use at higher temperatures. As it can be seen in Fig. 4 for the three ILs, the required PA and PL decreased with the temperature. This is consistent with the expected behavior, since an increased temperature is translated into a reduced viscosity and thus less energy is required to achieve the formation of the microdrops.
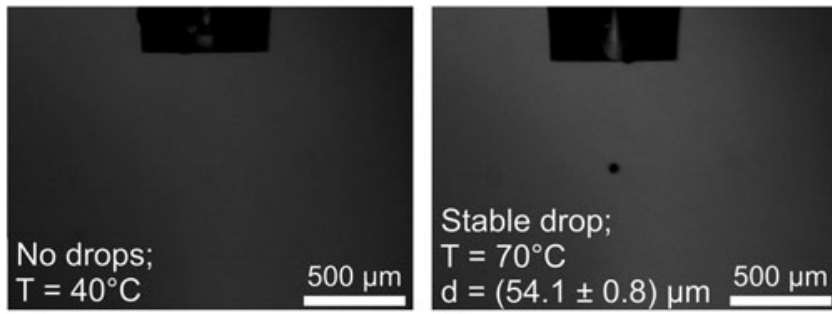

(a)

(b)

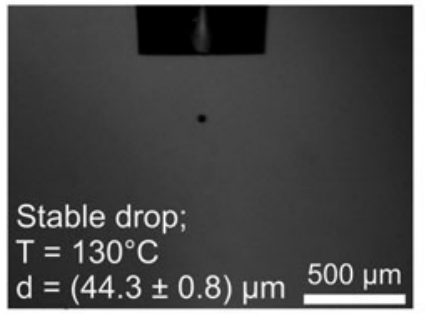

(c)

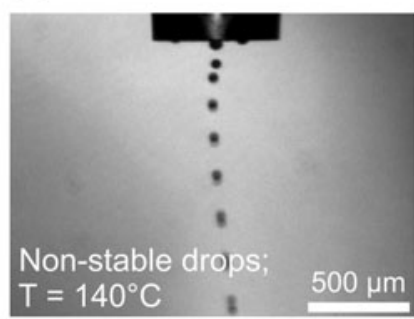

(d)

FIG. 3. Stroboscopic images of the IJP nozzle tip $300 \mu$ s after the pulse signal is sent at different temperatures of the nozzle.
This behavior is also consistent with the reduction of diameter of the ejected microdrops observed in Fig. 3. Figure 5 shows the evolution of the volume of the microdrops for each of the studied ILs. The volume is ranging between $141.1 \pm 0.5 \mathrm{pL}$ at $50{ }^{\circ} \mathrm{C}$ and $43 \pm 3 \mathrm{pL}$ at $120{ }^{\circ} \mathrm{C}$ for $\left[\mathrm{BF}_{4}\right]$, between $168 \pm 10 \mathrm{pL}$ at $60{ }^{\circ} \mathrm{C}$ and $86 \pm 3 \mathrm{pL}$ at $120^{\circ} \mathrm{C}$ for $\left[\mathrm{CH}_{3} \mathrm{SO}_{4}\right]$, and between $319 \pm 1 \mathrm{pL}$ at $60{ }^{\circ} \mathrm{C}$ and $191 \pm 3 \mathrm{pL}$ at $110{ }^{\circ} \mathrm{C}$ for $\left[\mathrm{PF}_{6}\right]$. Hence, for the
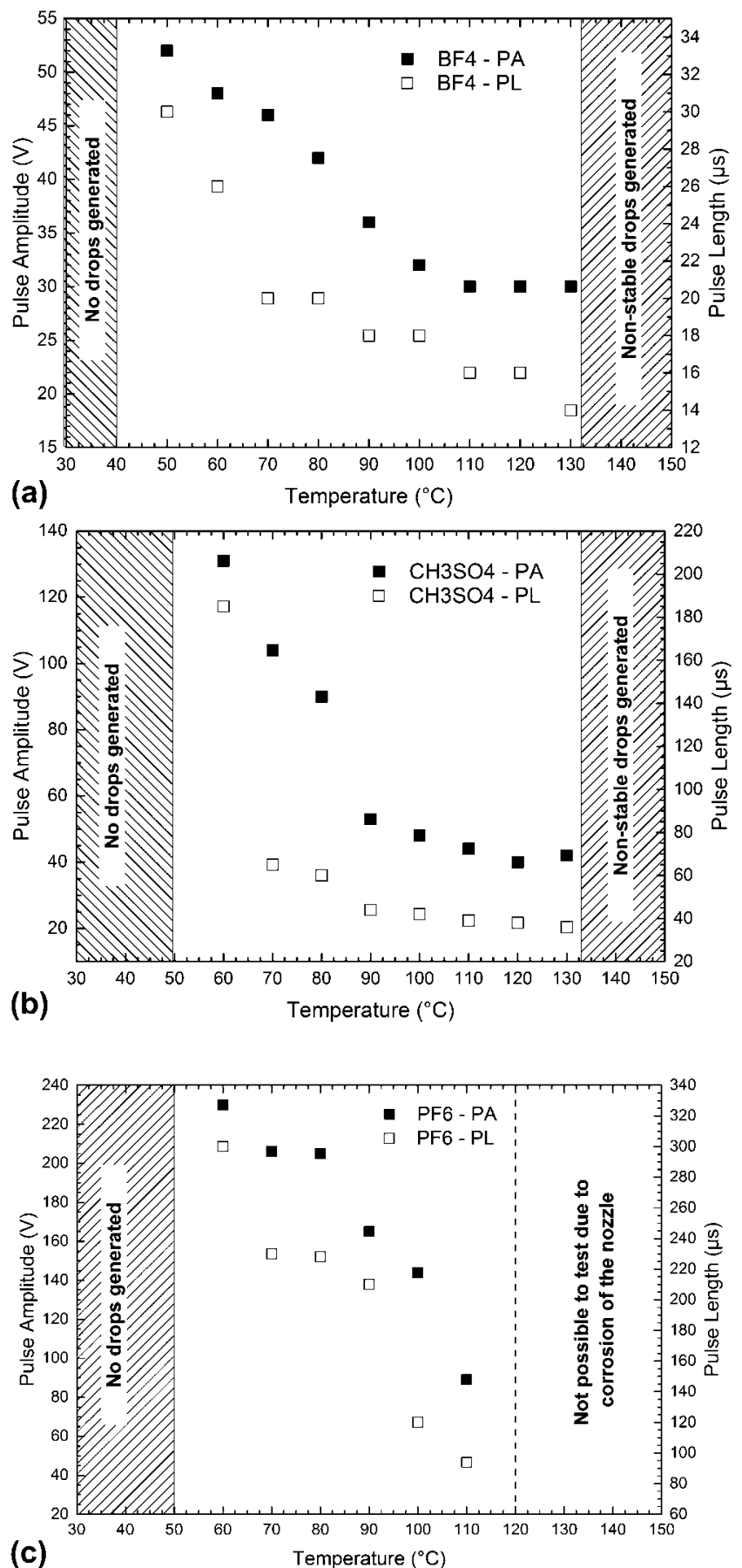

FIG. 4. Optimal IJP parameters (PA: left axis, PL: right axis) at different temperatures for (a) $\left[\mathrm{BF}_{4}\right]$, (b) $\left[\mathrm{CH}_{3} \mathrm{SO}_{4}\right]$, and (c) $\left[\mathrm{PF}_{6}\right]$. 
three materials, the volume decreases with the temperature as it was expected. For both $\left[\mathrm{BF}_{4}\right]$ and $\left[\mathrm{CH}_{3} \mathrm{SO}_{4}\right]$, the volume tends to stabilize at temperatures above $90{ }^{\circ} \mathrm{C}$ before reaching the nonstable microdrops region. The evolution of the volume is analogous to the one of the viscosity for these materials, ${ }^{38,40}$ indicating that the viscosity is driving the behavior of the volume in front of temperature. Although the surface tension is very similar for the three studied ILs, the density of $\left[\mathrm{PF}_{6}\right]$ is larger. This can explain the bigger volume measured for the microdrops of this liquid.

Although the results presented in Fig. 5 demonstrate that it is possible to control the deposited volume of the ILs by controlling the temperature, it will be difficult to control the volume at the picoliter range using this method. Nevertheless, it is possible to modify the volume of the formed microdrops at a fixed temperature controlling the IJP parameters, namely PA and PL. Figure 6 shows the volume of $\left[\mathrm{BF}_{4}\right]$ microdrops generated at a temperature of $110{ }^{\circ} \mathrm{C}$ for (a) a fixed PL of $16 \mu$ s and (b) a fixed PA of $34 \mathrm{~V}$. Both PA and PL were fixed at these values because it was experimentally observed that they were the ones allowing a larger range of possible volumes.

It was not possible to obtain microdrops for PAs smaller than $30 \mathrm{~V}$ and PLs below $12 \mu$ s, since the liquid did not have enough kinetic energy to overcome the surface energy of the meniscus and the viscous dissipation. On the other hand, nonstable microdrops were formed for PAs above $38 \mathrm{~V}$ and PLs larger than $18 \mu \mathrm{s}$. In both cases, the volume increases linearly with PA or PL, respectively, in the working range. For PA, the slope was $3.2 \pm 0.2 \mathrm{pL} / \mathrm{V}$ and the total range was $8 \mathrm{~V}$, resulting in a maximum variation of $26 \pm 5 \mathrm{pL}$. For PL, the slope was slightly larger, $3.9 \pm 0.5 \mathrm{pL} / \mu \mathrm{s}$, while the range was shorter, $6 \mu \mathrm{s}$, resulting in a maximum variation of $25 \pm 8 \mathrm{pL}$. Hence, it is possible to conclude that changes on PA and PL have equivalent effect in controlling the volume of the generated microdrop. However, PA exhibits a reduced deviation. So to achieve the highest precision, it would be recommended to optimize PL to generate the microdrops with the minimum deviation and then modify PA to obtain the desired volume. These results prove the capability of IJP not only to obtain very small volumes of ILs but also to control the exact amount of volume with high precision.

In addition to the detailed study performed for [BMIN] $\left[\mathrm{BF}_{4}\right],\left[\mathrm{CH}_{3} \mathrm{SO}_{4}\right]$, and $\left[\mathrm{PF}_{6}\right]$, the capacity to obtain microdrops using IJP has been tested for additional ILs with different cations and/or anions. Table II summarizes all the different ILs that have been tested. As can be seen in Table II, it was possible to generate microdrops of ILs with viscosities above $500 \mathrm{mPas}$ at $T_{\mathrm{R}}$. These results validate the capability and versatility of IJP to generate volumes of ILs in the picoliter range.

Additionally to the possibility to generate and control small volumes of ILs, IJP also provides the capability to deposit such small volumes at precise positions

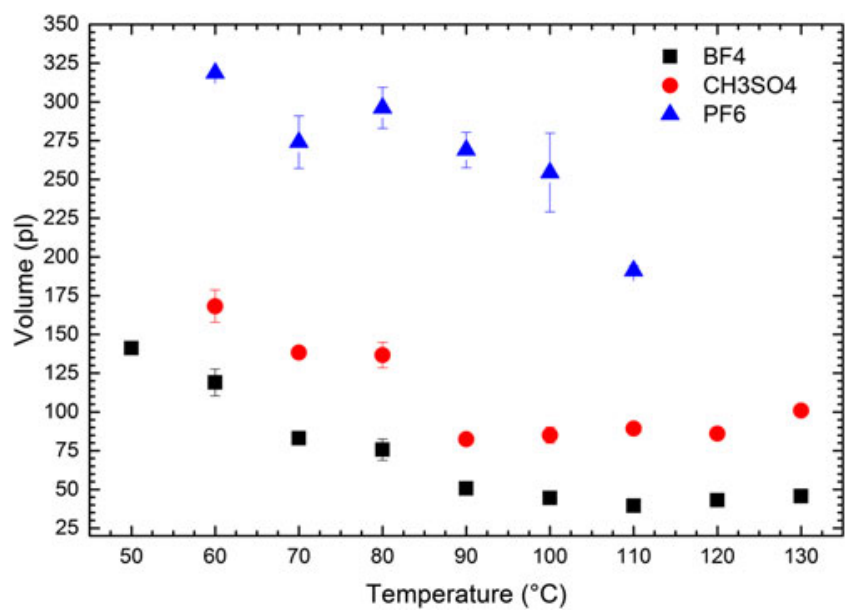

FIG. 5. Volume of the ejected microdrops versus temperature for $\left[\mathrm{BF}_{4}\right],\left[\mathrm{CH}_{3} \mathrm{SO}_{4}\right]$, and $\left[\mathrm{PF}_{6}\right]$.
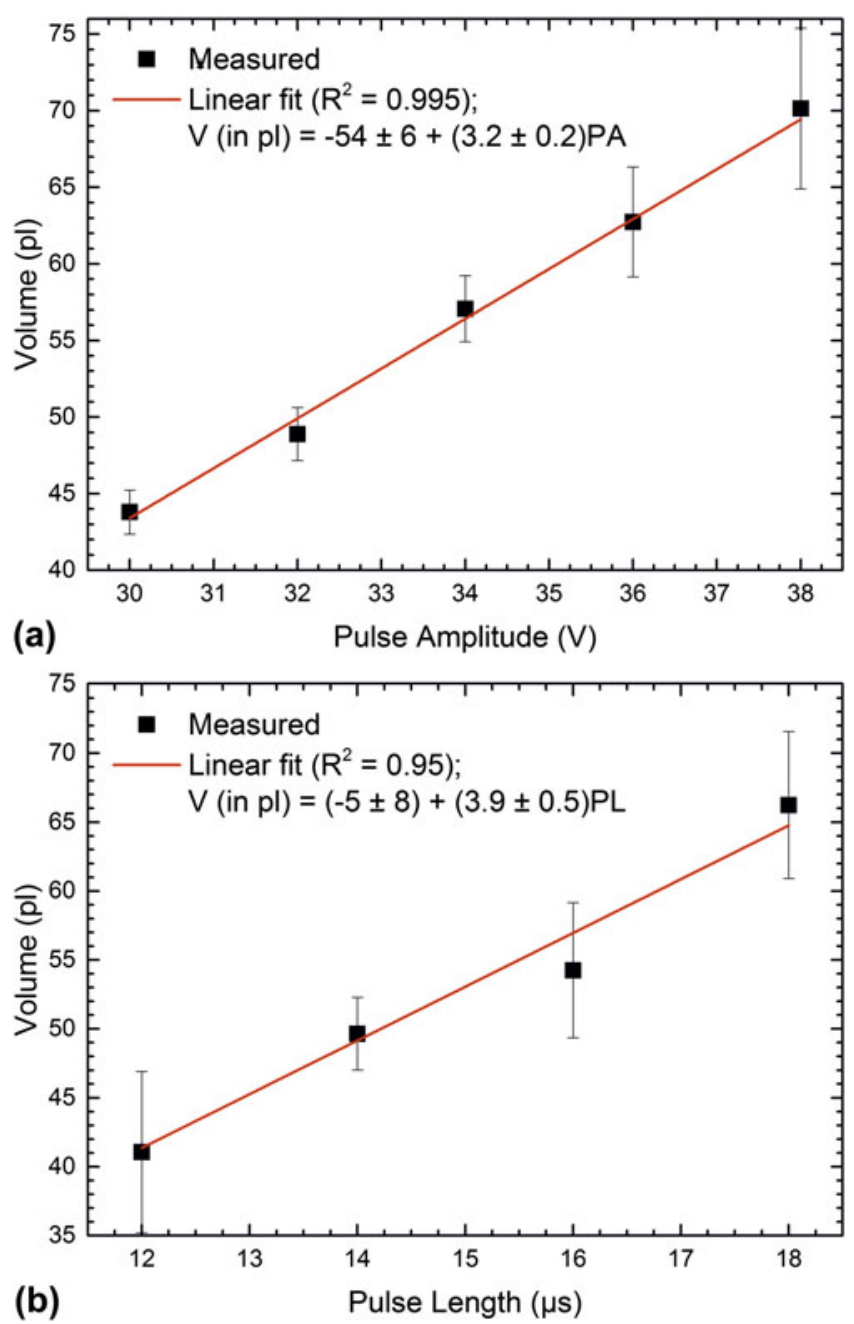

FIG. 6. Volume of $\left[\mathrm{BF}_{4}\right]$ ejected microdrops at a temperature of $110^{\circ} \mathrm{C}$ versus (a) PA for a fixed PL of $16 \mu$ s and (b) PL for a fixed PA of $34 \mathrm{~V}$. 
on a substrate, via DoD deposition. A silicon wafer has been used as the substrate for the deposition because it can be directly used to perform scanning electron microscope (SEM) images without any metallization. Figure 7 shows SEM images of two arrays of [BMIM] $\left[\mathrm{BF}_{4}\right]$ single microdrops deposited onto (a) bare $\mathrm{Si}$ and (b) Si with a SAM layer. The position of the microdrops was controlled by moving the substrates using an X-Y motorized stage. In both cases, each microdrop contains the same target volume $(43 \pm 3 \mathrm{pL})$ but the distribution of the ILs in the surface is drastically different. The ILs spread on the bare Si tending to form thin films. The microdrops deposited on the $\mathrm{Si}$ covered with a SAM layer tend to confine into high aspect ratio microdrops. This difference is due to the difference in the surface energy of both substrates and agrees with the expected behavior, as it has been observed and studied in a previous work. ${ }^{18}$ Since no solvent is involved in the process, the IL microdrops are deposited on the substrate with their final size and it is possible to place them with a high density. Using PS

TABLE II. Summary of the microdrop generation study for different ILs.

\begin{tabular}{llcc}
\hline \hline Cation & \multicolumn{1}{c}{ Anion } & $\mu$ at $T_{\mathrm{R}}(\mathrm{mPas})$ & Range of $T\left({ }^{\circ} \mathrm{C}\right)$ \\
\hline$[$ EMIM] & {$[\mathrm{Cl}]$} & 47.4 & $25-95$ \\
{$[$ EMIM] } & {$\left[\mathrm{BF}_{4}\right]$} & 66.5 & $25-105$ \\
{$[\mathrm{BMIM}]$} & {$\left[\mathrm{BF}_{4}\right]$} & 109 & $50-130$ \\
{$[\mathrm{BMIM}]$} & {$\left[\mathrm{CH}_{3} \mathrm{SO}_{4}\right]$} & 288 & $60-130$ \\
{$[\mathrm{HMIM}]$} & {$\left[\mathrm{BF}_{4}\right]$} & 314 & $50-130$ \\
{$[\mathrm{BMIM}]$} & {$\left[\mathrm{PF}_{6}\right]$} & 376 & $60-110^{\mathrm{a}}$ \\
{$[\mathrm{DMIM}]$} & {$\left[\mathrm{BF}_{4}\right]$} & $>500$ & $90-140$ \\
\hline \hline
\end{tabular}

${ }^{\mathrm{a}}$ Not possible to test higher temperature.

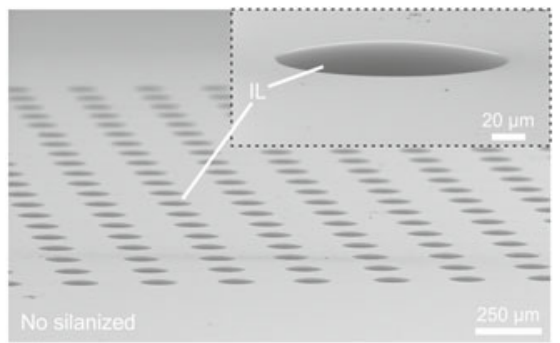

(a)

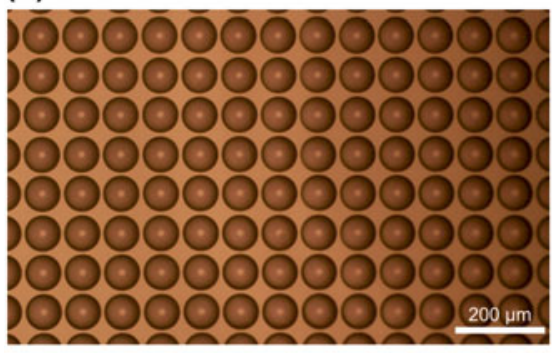

(c) as the substrate for the deposition, it was possible to reach a measured minimum distance between two microdrops of only $5 \mu \mathrm{m}$, equivalent to the precision in the experimental setup. Such dense microdrops array has subsequently been replicated into PDMS. This replication process has been previously demonstrated ${ }^{18}$ but in this work we extend this work toward ordered arrays with a well-controlled volume on each microdrop. The replicated array can be seen in Fig. 7(c). The replicated structures can be directly used as concave lenses, as shown in Fig. 7(d) by superimposing the microlens array onto the printed EPFL logo, magnifying it, or as a mold for the fabrication of convex microlenses into polymeric materials. The capability to obtain and reproduce distributed IL arrays with controlled volume is of capital relevance for the use of this technique in future applications.

\section{CONCLUSIONS}

In this paper, the generation of IL microdrops using IJP has been studied for materials with viscosities at room temperature $\left(T_{\mathrm{R}}\right)$ up to $500 \mathrm{mPas}$, with a total of 7 different ILs tested. A dimensionless analysis done on 3 different ILs with viscosities above $100 \mathrm{mPas}$ shows that, although such materials are not printable at $T_{\mathrm{R}}$, it is possible to determine the minimum temperature necessary to achieve stable microdrop generation. The experimental results have validated this study showing that microdrop generation is only possible for temperatures above $50{ }^{\circ} \mathrm{C}$ or $60{ }^{\circ} \mathrm{C}$, and that nonstable drops start appearing for temperatures above $130{ }^{\circ} \mathrm{C}$. IJP parameters, namely pulse amplitude (PA) and pulse length (PL), have been optimized

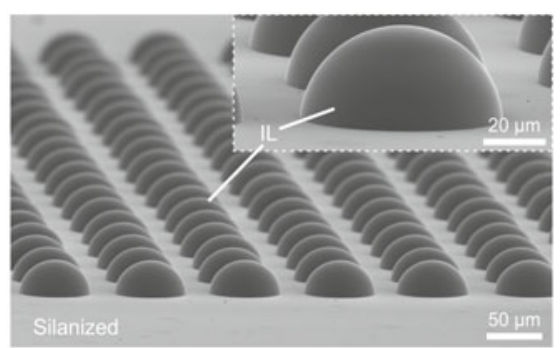

(b)

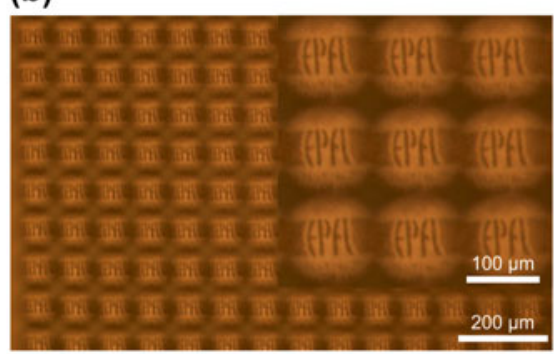

(d)

FIG. 7. SEM pictures of $\left[\mathrm{BF}_{4}\right]$ deposited over (a) a bare silicon substrate and (b) a silicon substrate with SAM layer. Optical microscope images of (c) a PDMS replica of an array of $\left[\mathrm{BF}_{4}\right]$ microdrops and $(\mathrm{d})$ the same array acting as a lens, while superimposed to the printed EPFL logo. 
to obtain the smallest possible volume per microdrop at each temperature, ranging between $43 \pm 3 \mathrm{pL}$ for [BMIM] $\left[\mathrm{BF}_{4}\right]$ at $120^{\circ} \mathrm{C}$ and $319 \pm 1 \mathrm{pL}$ for $[\mathrm{BMIM}]\left[\mathrm{PF}_{6}\right]$ at $60^{\circ} \mathrm{C}$. Furthermore, we showed that it is possible to control the volume of a microdrop with a variation of $3.2 \mathrm{pL}$ by tuning the IJP parameters at a fixed temperature. We also demonstrated the deposition of the IL microdrops onto a substrate with high position control in the order of $5 \mu \mathrm{m}$. As a proof of concept, an array of IL microdrops has been replicated into PDMS to be used as a concave microlens array. These results demonstrate that it is possible to generate and precisely place small volumes of ILs, which is of great relevance for a large number of applications, as for example in micro-chemical devices, MEMS/NEMS, microreactors, sensing, solar energy microsystems, and so forth.

\section{ACKNOWLEDGMENTS}

This work has been partially funded by the IAPP Marie Curie action ACAPOLY (no PIAP-GA-2008-218075) of the 7th Framework Program of the EU, the Spanish Ministry for Science and Technology (MAT2009-14695-C04-01), the Junta of Extremadura (GRU10149), and FEDER. Julia Perera-Nuñez acknowledges Junta de Extremadura for a predoctoral grant. The authors are pleased to acknowledge the EPFL Center of MicroNano Technology (CMI) for their valuable discussions and help.

\section{REFERENCES}

1. N.V. Plechkova and K.R. Seddon: Applications of ionic liquids in the chemical industry. Chem. Soc. Rev. 37(1), 123 (2008).

2. R.D. Rogers and K.R. Seddon: Ionic liquids - Solvents of the future? Science 302(5646), 792 (2003).

3. H. Weingärtner: Understanding ionic liquids at the molecular level: Facts, problems, and controversies. Angew. Chem., Int. Ed. 47(4), 654 (2008).

4. K.R. Seddon: Ionic liquids for clean technology J. Chem. Technol. Biotechnol. 68(4), 351 (1997).

5. P. Wasserscheid and W. Keim: Ionic liquids - New 'solutions' for transition metal catalysis. Angew. Chem., Int. Ed. 39(21), 3773 (2000).

6. T. Torimoto, T. Tsuda, K.I. Okazaki, and S. Kuwabata: New frontiers in materials science opened by ionic liquids. Adv. Mater. 22(11), 1196 (2010).

7. E.F. Borra, O. Seddiki, R. Angel, D. Eisenstein, P. Hickson, K.R. Seddon, and S.P. Worden: Deposition of metal films on an ionic liquid as a basis for a lunar telescope. Nature 447(7147), 979 (2007).

8. M. Grätzel: Dye-sensitized solar cells. J. Photochem. Photobiol., C 4(2), 145 (2003).

9. T.T. Trang Pham, T. Bessho, N. Mathews, S.M. Zakeeruddin, Y.M. Lam, S. Mhaisalkar, and M. Grätzel: Light scattering enhancement from sub-micrometer cavities in the photoanode for dye-sensitized solar cells. J. Mater. Chem. 22(32), 16201 (2012).

10. F.J.M. Rutten, H. Tadesse, and P. Licence: Rewritable imaging on the surface of frozen ionic liquids. Angew. Chem., Int. Ed. 46(22), 4163 (2007).
11. M.D. Bermúdez, A.E. Jiménez, J. Sanes, and F.J. Carrión: Ionic liquids as advanced lubricant fluids. Molecules 14(8), 2888 (2009).

12. G.T. Kim, S.S. Jeong, M.Z. Xue, A. Balducci, M. Winter, S. Passerini, F. Alessandrini, and G.B. Appetecchi: Development of ionic liquid-based lithium battery prototypes. J. Power Sources 199, 239 (2012).

13. N. Liu, X. Chen, and Z. Ma: Ionic liquid functionalized graphene/ $\mathrm{Au}$ nanocomposites and its application for electrochemical immunosensor. Biosens. Bioelectron. 48, 33 (2013).

14. D. Tordera, S. Meier, M. Lenes, R.D. Costa, E. Ortí, W. Sarfert, and H.J. Bolink: Simple, fast, bright, and stable light sources. Adv. Mater. 24(7), 897 (2012).

15. S. Tsuchitani, N. Takagi, K. Kikuchi, and H. Miki: Chemical propulsion using ionic liquids. Langmuir 29(9), 2799 (2013).

16. A. Hozumi, P. Bien, and T.J. McCarthy: Ionic liquids: Nondestructive, nonvolatile imaging fluids for submicrometer-scale monolayer patterns. J. Am. Chem. Soc. 132(16), 5602 (2010).

17. P. Dubois, G. Marchand, Y. Fouillet, J. Berthier, T. Douki, F. Hassine, S. Gmouh, and M. Vaultier: Ionic liquid droplet as e-microreactor. Anal. Chem. 78(14), 4909 (2006).

18. J. Perera-Núñez, A. Méndez-Vilas, L. Labajos-Broncano, and M.L. González-Martín: Ionic liquid microdroplets as versatile lithographic molds for sculpting curved topographies on soft materials surfaces. Langmuir 26(22), 17712 (2010).

19. L. Gao and T.J. McCarthy: Ionic liquids are useful contact angle probe fluids. J. Am. Chem. Soc. 129(13), 3804 (2007).

20. M. Palacio and B. Bhushan: Ultrathin wear-resistant ionic liquid films for novel MEMS/NEMS applications. Adv. Mater. 20(6), 1194 (2008).

21. J. Pu, S. Wan, W. Zhao, Y. Mo, X. Zhang, L. Wang, and Q. Xue: Preparation and tribological study of functionalized graphene-IL nanocomposite ultrathin lubrication films on Si substrates. J. Phys. Chem. C 115(27), 13275 (2011).

22. A. Inaba, G. Yoo, Y. Takei, K. Matsumoto, and I. Shimoyama: A Graphene FET Gas Sensor Gated by Ionic Liquid: Proceedings of the IEEE 26th International Conference on Micro Electro Mechanical Systems (Taipei, Taiwan, 2013); p. 969.

23. X. Mu, Z. Wang, M. Guo, X. Zeng, and A.J. Mason: Fabrication of a Miniaturized Room Temperature Ionic Liquid Gas Sensor for Human Health and Safety Monitoring: Proceedings of the IEEE Biomedical Circuits and Systems Conference: Intelligent Biomedical Electronics and Systems for Better Life and Better Environment (Hsinchu, Taiwan, 2012); p. 140.

24. X. Mu, Z. Wang, X. Zeng, and A.J. Mason: A robust flexible electrochemical gas sensor using room temperature ionic liquid. IEEE Sens. J. 13(10), 3976 (2013).

25. K. Ohsawa, H. Takahashi, K. Noda, T. Kan, K. Matsumoto, and I. Shimoyama: A Gas Sensor Based on Viscosity Change of Ionic Liquid: Proceedings of the 24th IEEE International Conference on Micro Electro Mechanical Systems (Cancun, Mexico, 2011); p. 525.

26. K. Kaisei, K. Kobayashi, K. Matsushige, and H. Yamada: Fabrication of ionic liquid thin film by nano-inkjet printing method using atomic force microscope cantilever tip. Ultramicroscopy 110(6), $733(2010)$

27. J.T. Delaney, Jr., A.R. Liberski, J. Perelaer, and U.S. Schubert: A practical approach to the development of inkjet printable functional ionogels - bendable, foldable, transparent, and conductive electrode materials. Macromol. Rapid Commun. 31(22), 1970 (2010).

28. U. Löffelmann, N. Wang, D. Mager, P.J. Smith, and J.G. Korvink: Solvent-free inkjet printing process for the fabrication of conductive, transparent, and flexible ionic liquid-polymer gel structures. J. Polym. Sci., Part B: Polym. Phys. 50(1), 38 (2012).

29. V.J. Cadarso, J. Perera-Núñez, L. Jacot-Descombes, K. Pfeiffer, U. Ostrzinski, A. Voigt, A. Llobera, G. Grützer, and J. Brugger: Microlenses with defined contour shapes. Opt. Express 19(19), 18665 (2011). 
30. V.J. Cadarso, G. Smolik, V. Auzelyte, L. Jacot-Descombes, and J. Brugger: Heterogeneous material micro-transfer by ink-jet print assisted mould filling. Microelectron. Eng. 98, 619 (2012).

31. B.J. De Gans, P.C. Duineveld, and U.S. Schubert: Inkjet printing of polymers: State of the art and future developments. Adv. Mater. 16(3), 203 (2004).

32. H. Wijshoff: The dynamics of the piezo inkjet printhead operation. Phys. Rep. 491(4-5), 77 (2010).

33. G.O. Thomas: The aerodynamic breakup of ligaments. Atomization Sprays 13(1), 117 (2003).

34. Y.F. Liu, M.H. Tsai, Y.F. Pai, and W.S. Hwang: Control of droplet formation by operating waveform for inks with various viscosities in piezoelectric inkjet printing. Appl. Phys. A: Mater. Sci. Process. 111(2), 509 (2013).

35. B. Derby: Inkjet printing ceramics: From drops to solid. J. Eur. Ceram. Soc. 31(14), 2543 (2011).
36. J.E. Fromm: Numerical calculation of the fluid dynamics of dropon-demand jets IBM. J. Res. Dev. 28(3), 322 (1984).

37. N. Reis, C. Ainsley, and B. Derby: Ink-jet delivery of particle suspensions by piezoelectric droplet ejectors. J. Appl. Phys. 97(9), (2005).

38. J. Jacquemin, P. Husson, A.A.H. Padua, and V. Majer: Density and viscosity of several pure and water-saturated ionic liquids. Green Chem. 8(2), 172 (2006).

39. M.G. Freire, P.J. Carvalho, A.M. Fernandes, I.M. Marrucho, A.J. Queimada, and J.A.P. Coutinho: Surface tensions of imidazolium based ionic liquids: Anion, cation, temperature and water effect. J. Colloid Interface Sci. 314(2), 621 (2007).

40. A.B. Pereiro, P. Verdía, E. Tojo, and A. Rodríguez: Physical properties of 1-butyl-3-methylimidazolium methyl sulfate as a function of temperature. J. Chem. Eng. Data 52(2), 377 (2007). 